\title{
Measurements of buccal gingival and alveolar crest thicknesses of premolars using a noninvasive method
}

\author{
Meng Sun', Wei Yao², Yongqiang Deng', Jun Cao², He Meng²
}

${ }^{1}$ Department of Ultrasound Diagnostics and Treatment, Shenzhen Second People's Hospital, First Affiliated Hospital of Shenzhen University, ${ }^{2}$ Department of Stomatology, Shenzhen University General Hospital and Shenzhen University Clinical Medical Academy, Shenzhen, Guangdong, China

\begin{abstract}
Aims: Knowledge of gingival thickness (GT) and alveolar crest thickness (ACT) is essential for performing various surgical and non-surgical procedures in oral healthcare. However, a noninvasive, no-radiation and reproducible method for measuring GT and ACT is not yet determined. This study aimed to measure the buccal GT and ACT of premolars using 15-MHz B-mode ultrasonography (US) and to explore the relationship between GT and ACT. Material and methods: The GT in four swine mandibles was measured using 15-MHz B-mode US and using K-file needles to gauge the accuracy of US. B-mode US at $15 \mathrm{MHz}$ was also used to measure periodontal tissue structures including buccal GT3 (3 mm apical to the gingival margin) and ACT in 400 premolars of 50 human participants with healthy periodontium. Results: There was a strong positive correlation between US and invasive K-file needle measurements of GT in swine mandibles $(\mathrm{p}<0.05)$. The correlation between buccal GT3 and ACT of premolars was moderately positive $(p<0.05)$. The gingiva of the maxillary premolars and ACT of the maxillary first premolars were thicker in men than in women $(\mathrm{p}<0.05)$. Conclusions: B-mode US at $15 \mathrm{MHz}$ is a valid and reliable method for measuring GT and ACT and for evaluating their relationship.
\end{abstract}

Keywords: gingival thickness; premolar; periodontal anatomy; ultrasonography; alveolar crest thickness

\section{Introduction}

The assessment of gingival thickness (GT) and alveolar bone thickness (ACT) of teeth is the key for determining the correct diagnosis, prognosis and mechanism of healing in many oral treatments. The response of the gingiva to inflammation, restorative trauma, and surgical insult differs according to its thickness. Patients with thicker gingiva develop periodontal pockets secondary to

Received 28.03.2020 Accepted 22.05.2020

Med Ultrason

2020, Vol. 22, No 4, 409-414

Corresponding author: He Meng

Department of Stomatology, Shenzhen University

General Hospital and Shenzhen University

Clinical Medical Academy,

Liuxian Street, Nanshan district, Shenzhen,

Guangdong 518055, China

Phone: +86 13265627399

Fax: 0755-21839000

E-mail: menghe10.2@163.com inflammation caused by bacterial plaque accumulation, whereas patients with thinner gingiva are more prone to gingival recession $[1,2]$. GT normally refers to the thickness of buccal or facial gingiva. Studies have reported that ACT is a significant factor affecting the correct implant placement and attainment of adequate esthetic outcomes $[3,4]$. Therefore, many surgeries are devoted to ACT reconstruction $[5,6]$. Hence, it is known that GT and underlying ACT play decisive roles in treatment outcomes.

The methods used to measure GT and ACT are classified as invasive and noninvasive. Invasive methods involve direct bone sounding using periodontal probes or injection needles [4-8]. Such practices tend to cause discomfort and require local anesthesia; therefore, the use of noninvasive techniques, such as visual assessment and the transparency method for measuring GT, are gaining increased popularity among dental practitioners $[9,10]$. However, assessment of GT by visual tissue inspection has been shown to be unreliable $[11,12]$. Although com- 
puted tomography (CT) has been used as a noninvasive technique to measure hard and soft tissue thicknesses [13-15], exposing patients to radiation may not always be justified for this particular indication.

Ultrasonography (US) is a noninvasive and painless type of diagnostic imaging that does not expose patients to radiation. Additionally, the continuous improvements in US for measurements of oral soft and hard tissues have been underway for at least a decade. One study that assessed a custom-made $50 \mathrm{MHz}$ A-mode US dental system demonstrated that the accuracy of GT measurements acquired by US was equivalent to that of those acquired by invasive methods [16]. A cadaveric study that compared $5 \mathrm{MHz}$ A-mode US and micro-CT demonstrated a strong correlation between the validity and reproducibility in measurements of mucosal thickness [17]. Although A-mode US devices are moderately accurate for measurements of GT at a particular point, their accuracy might be limited in determining the average GT and ACT; they cannot provide a panoramic view of the gingival and periodontal structures or analyze their relationship adequately.

In contrast, B-mode US can measure buccal GT and $\mathrm{ACT}$ and can also analyze the periodontal tissue structures. One study used $40 \mathrm{MHz}$ B-mode US to measure the premolar GT in four patients and found that it was a noninvasive and highly accurate technique for measuring GT and assessing the periodontium [18]. While this type of very-high frequency B-mode US is not widely available for clinical use, B-mode US is widely used at $15 \mathrm{MHz}$ and is an accessible instrument. However, a literature search did not yield any studies that used $15 \mathrm{MHz}$ B-mode US to investigate the structures of periodontal tissues in humans.

Therefore, the aim of this study was to evaluate whether $15 \mathrm{MHz}$ B-mode US is an efficient, convenient and accessible tool that can be used to assess the periodontal tissue structures of premolars and to explore the relationship between GT and ACT.

\section{Materials and methods}

\section{Measurements using $15 \mathrm{MHz}$ B-mode US and an invasive method in swine mandibles}

This study used a Logiq E9 machine (General Electric Company, Boston, MA, USA) with linear probe (ML 6-15), to measure the GT in swine mandibles. The validity of the $15 \mathrm{MHz}$ B-mode US measurements was assessed in four mandibles from freshly slaughtered 8- to 10-month-old domestic swine. We measured the GT of posterior teeth on the lingual sides of mandibles and attempted to identify the cementoenamel junction (CEJ), root, gingiva, alveolar bone, and alveolar crest at its coronal limit. The working width of the US probe was 10 $\mathrm{mm}$ and there were $3 \mathrm{~mm}$ markings (non-working edges) on both sides (fig 1). We marked blue lines within a dis-
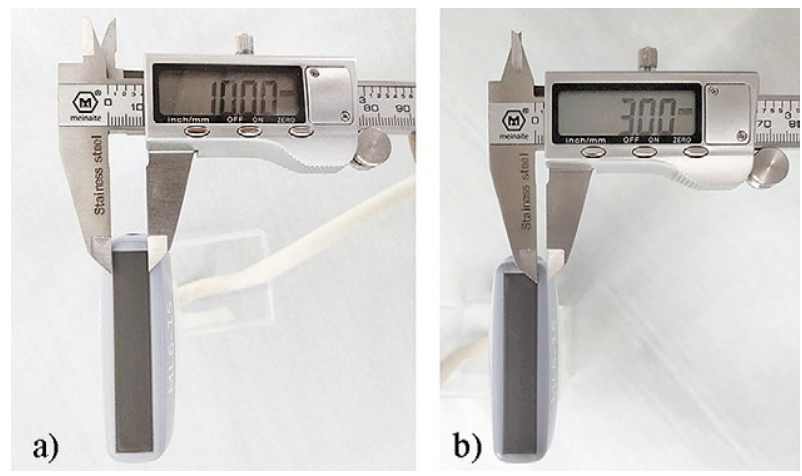

Fig 1. The ML6-15 MHz probe (General Electric Company, Boston, USA).A. working width of the US probe is $10 \mathrm{~mm}$. B. The edge (non-working parts) of the probe is $3 \mathrm{~mm}$.

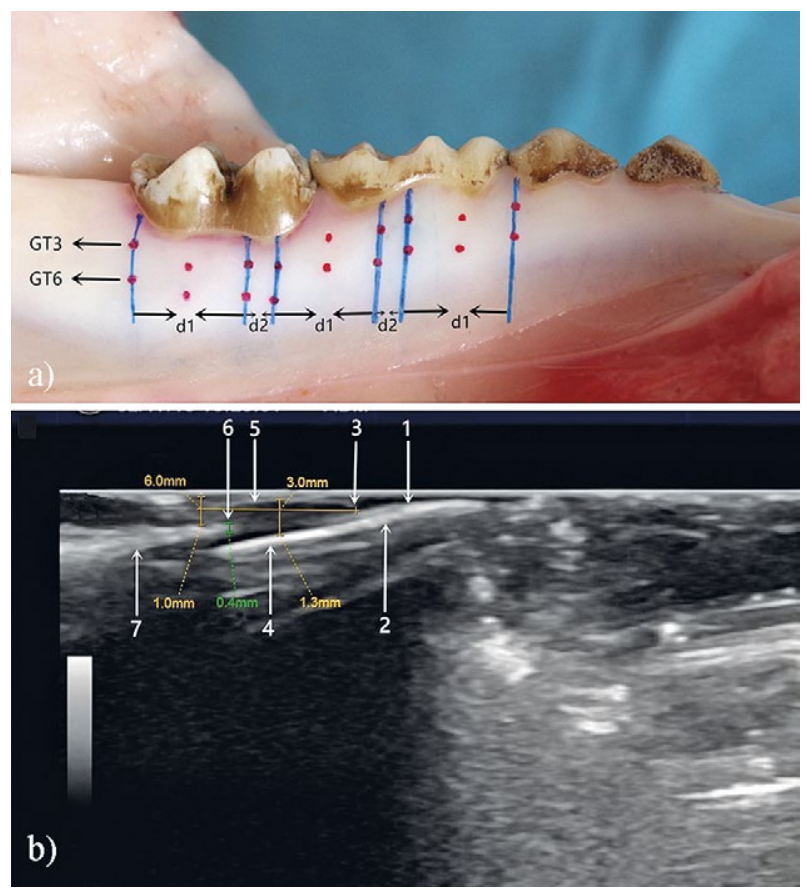

Fig 2. Measurement of gingival thickness in a swine mandible using ultrasonography and an invasive method. (A) Determination of gingival thickness at GT3 and GT6 in a swine mandible. The mandible is marked as follows: red dots represent penetration points; areas between the blue lines represent locations where the ultrasonography probe is placed where the K-file needle is placed ( $\mathrm{d} 1=10 \mathrm{~mm}, \mathrm{~d} 2=3 \mathrm{~mm})$. (B) A sagittal ultrasonographic image through a swine tooth visualizing the following elements: 1 , crown enamel; 2 , cementoenamel junction; 3, gingival margin; 4, tooth root; 5 , gingiva; 6 , alveolar crest (coronal edge); and 7, alveolar bone. GT3, $3 \mathrm{~mm}$ apical to the gingival margin; GT6, $6 \mathrm{~mm}$ apical to the gingival margin. 
tance of $10 \mathrm{~mm}$. We marked 3 points (mesial, middle, and distal) within the working area of $10 \mathrm{~mm}$, at $3 \mathrm{~mm}$ (GT3) and $6 \mathrm{~mm}$ (GT6) apical to the gingival margin, resulting in a total of 6 points within the working area (fig 2a). The gingival margin was the reference point clearly seen in the US image. The GT was measured at GT3 and GT6 apical to the gingival margin (fig 2b). GT was also measured using a K-file needle with a rubber stopper and Vernier calipers at the same locations. For each location, three points (i.e., mesial, middle, and distal) in the gingiva of mandibular posterior teeth were selected for needle piercing. The K-file needle was carefully inserted at each point until resistance was encountered, and was withdrawn. The penetration depth was determined using a digital caliper with an accuracy of 0.01 $\mathrm{mm}$ (Deli Corporation, Ningbo, China).

\section{Measurements using $15 \mathrm{MHz} B$-mode US \\ in human participants}

Study participants

This study was independently reviewed and approved by the Research Ethics Committee of our institute and conducted in accordance with the Declaration of Helsinki. The study participants were recruited from our institute and included students, staff and patients without any periodontal disease from the General Hospital's Department of Stomatology. We obtained written informed consent from all study participants before enrollment. Clinical examinations of the maxillary and mandibular premolars were performed, which included measurements of pocket depth, clinical attachment level, and bleeding on assessment with a periodontal probe (Hu-Friedy, Chicago,IL, USA). Only adults with healthy periodontal tissues (pocket depth $\leq 3 \mathrm{~mm}$ with no attachment loss or bleeding) were enrolled in the study. The exclusion criteria were as follows: systemic disease with oral manifestations; pregnancy or lactation; current use of medications that cause changes in periodontal tissues; mouth breathing; endodontic pathology in the premolar region; previous periodontal surgery; history of orthodontic treatment; malpositioned teeth, skeletal or maxillofacial abnormalities, crowding or spacing of teeth, and teeth with abnormal morphology of the crown or root; and current smoking.

\section{Clinical B-mode US examination}

Fifty periodontally healthy participants (25 men; mean age 25.8 \pm 4.4 [range,18-35] years) and their 400 premolar teeth were included in this study. The premolars were imaged with the $15 \mathrm{MHz}$ B-mode US device from the buccal side. The probe was adjusted such that it was placed on the surface of maxillary or mandibular lip in the transverse plane to identify the incisors. Thereafter, gradually, the probe was moved posteriorly to the premolars. Subsequently, the probe was placed at the center of the premolar and was rotated 90 degrees. The thicknesses of the soft and hard tissues and the periodontal tissues, including GT and ACT, were measured in the sagittal plane.

\section{Statistical analysis}

Continuous variables with a normal distribution and equal variance were analyzed using the Student's $t$-test and were expressed as a mean \pm standard deviation. Spearman's correlation was used to assess the correlations between variables. All statistical analyses were performed using SPSS 20.0 sofwtware (IBM Corp., Armonk, NY, USA). A p-value $<0.05$ was considered statistically significant.

\section{Results}

\section{Measurements using $15 \mathrm{MHz} B$-mode US}

and an invasive method in swine mandibles

Images obtained by $15 \mathrm{MHz}$ B-mode US clearly identified the anatomical reference points (fig $2 \mathrm{~b}$ ). The average GT3 measured using US was $1.57 \pm 0.45 \mathrm{~mm}$ and
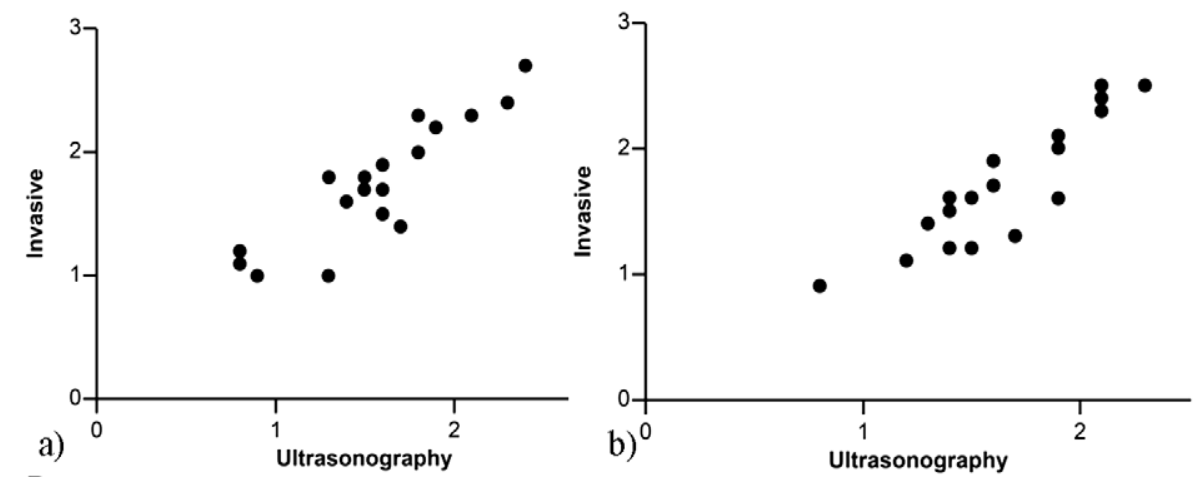

Fig 3. Correlation between values of gingival thickness measured by ultrasonography and an invasive method at GT3 (A) and GT6 (B). GT3, $3 \mathrm{~mm}$ apical to the gingival margin; GT6, $6 \mathrm{~mm}$ apical to the gingival margin. 
Table I. Comparison of gingival thicknesses in swine mandibles at two different locations using ultrasonographic and invasive methods.

\begin{tabular}{lllll}
\hline Location & Method & Mean \pm SD & Correlation & p-value \\
\hline GT3 $(\mathrm{mm})$ & US & $1.57 \pm 0.45$ & $r=0.83$ & $<0.01$ \\
& Invasive & $1.76 \pm 0.50$ & & \\
GT6 $(\mathrm{mm})$ & US & $1.65 \pm 0.38$ & $r=0.89$ & $<0.01$ \\
& Invasive & $1.71 \pm 0.49$ & & \\
\hline
\end{tabular}

GT3, $3 \mathrm{~mm}$ apical to the gingival margin; GT6, $6 \mathrm{~mm}$ apical to the gingival margin; SD, standard deviation; US, ultrasonography

those measured using the invasive method was $1.76 \pm 0.50$ $\mathrm{mm}$; the respective GT6 values were $1.65 \pm 0.38 \mathrm{~mm}$ and $1.71 \pm 0.49 \mathrm{~mm}$ (Table I). Although the US values were moderately smaller than the invasive-method values, there was a strong positive correlation between them at GT3 $(r=0.83, \mathrm{p}<0.01)$ and GT6 $(r=0.89, \mathrm{p}<0.01)$ (fig 3).

\section{Measurements using $15 \mathrm{MHz}$ B-mode US \\ in human participants}

The periodontal tissue structures were clearly visualized using $15 \mathrm{MHz}$ B-mode US (fig 4). The mean buccal GT3 and ACT at different locations on the premolars in men and women ranged from $0.90 \mathrm{~mm}$ to $1.35 \mathrm{~mm}$ (Table II) and from $0.60 \mathrm{~mm}$ to $1.29 \mathrm{~mm}$ (Table III), respectively. A comparison between GT3 and ACT in men and women at the same location on a tooth revealed that the gingiva of maxillary premolars in men was significantly thicker than the gingiva of maxillary premolars in women $(p<0.05)$. Additionally, ACT in men was significantly more than that in women; however, this difference in ACT was only observed in the maxillary first premolars. The correlation between buccal GT3 and ACT of premolars was moderately positive $(r=0.43, \mathrm{p}<0.01)$.

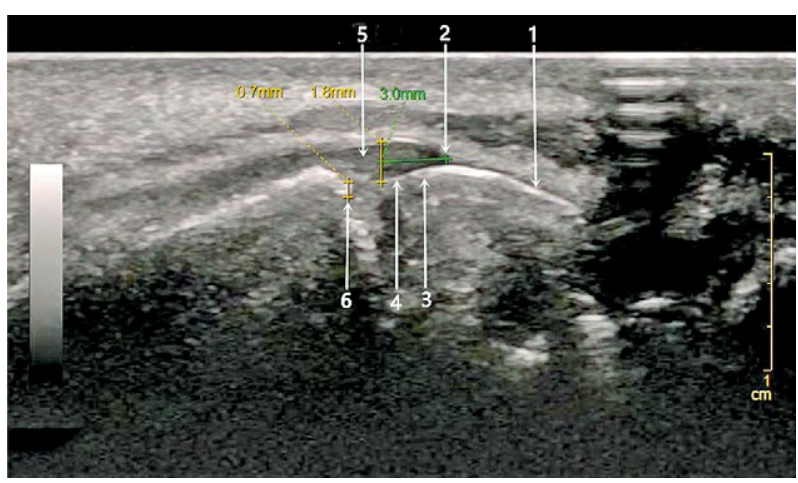

Fig 4. A15-MHz B-mode ultrasonographic image of the periodontal structures of a maxillary premolar. A sagittal ultrasonographic image through a maxillary premolar. The tick marks on the right side of the image indicate $1 \mathrm{~mm}$. 1, enamel; 2, gingival margin; 3 , cementoenamel junction; 4 , cementum; 5 , gingiva; and 6 , crest of alveolar bone.
Table II. Comparison of GT3 measurements of premolars in men and women.

\begin{tabular}{|c|c|c|c|c|}
\hline $\begin{array}{l}\text { Measure- } \\
\text { ment of } \\
\text { GT3 }(\mathrm{mm})\end{array}$ & $\begin{array}{l}\text { Men } \\
(\text { mean } \pm \text { SD })\end{array}$ & $\begin{array}{l}\text { Women } \\
(\text { mean } \pm \text { SD })\end{array}$ & p-value & $\begin{array}{l}\text { Signifi- } \\
\text { cance }\end{array}$ \\
\hline $\begin{array}{l}\text { Maxillary } \\
\text { first } \\
\text { premolars }\end{array}$ & $1.26 \pm 0.44$ & $0.94 \pm 0.47$ & 0.04 & $\mathrm{~S}$ \\
\hline $\begin{array}{l}\text { Maxillary } \\
\text { second } \\
\text { premolars }\end{array}$ & $1.35 \pm 0.49$ & $1.09 \pm 0.54$ & 0.03 & $\mathrm{~S}$ \\
\hline $\begin{array}{l}\text { Mandibular } \\
\text { first } \\
\text { premolars }\end{array}$ & $1.09 \pm 0.47$ & $0.96 \pm 0.23$ & 0.16 & NS \\
\hline $\begin{array}{l}\text { Mandibular } \\
\text { second } \\
\text { premolars }\end{array}$ & $1.05 \pm 0.46$ & $0.90 \pm 0.23$ & 0.13 & NS \\
\hline
\end{tabular}

GT3, $3 \mathrm{~mm}$ apical to the gingival margin; NS, not statistically significant; S, statistically significant; $\mathrm{SD}$, standard deviation

Table III. Comparison of ACT of premolars between men and women.

\begin{tabular}{lllll}
\hline $\begin{array}{l}\text { Measure- } \\
\text { ment of } \\
\text { ACT }(\mathbf{m m})\end{array}$ & $\begin{array}{l}\text { Men } \\
(\text { mean } \pm \text { SD) }\end{array}$ & $\begin{array}{l}\text { Women } \\
(\text { mean } \pm \text { SD) }\end{array}$ & p-value & $\begin{array}{l}\text { Signifi- } \\
\text { cance }\end{array}$ \\
\hline $\begin{array}{l}\text { Maxillary } \\
\text { first } \\
\text { premolars }\end{array}$ & $1.29 \pm 0.58$ & $0.80 \pm 0.39$ & 0.00 & $\mathrm{~S}$ \\
$\begin{array}{l}\text { Maxillary } \\
\text { second }\end{array}$ & $0.90 \pm 0.30$ & $0.81 \pm 0.37$ & 0.34 & $\mathrm{NS}$ \\
premolars & & & & \\
$\begin{array}{l}\text { Mandibular } \\
\text { first } \\
\text { premolars }\end{array}$ & $0.69 \pm 0.21$ & $0.62 \pm 0.22$ & 0.29 & $\mathrm{NS}$ \\
$\begin{array}{l}\text { Mandibular } \\
\text { second }\end{array}$ & $0.72 \pm 0.29$ & $0.60 \pm 0.19$ & 0.05 & $\mathrm{NS}$ \\
premolars & & & & \\
\hline
\end{tabular}

ACT, alveolar crest thicknesses; NS, not statistically significant; S, statistically significant; SD, standard deviation

\section{Discussions}

This study attempted to validate the efficacy of 15 $\mathrm{MHz}$ B-mode US in analyzing the anatomic structure of premolars and buccal GT3 and ACT in these teeth. Our results confirmed that the $15 \mathrm{MHz}$ B-mode US probe clearly and accurately detected the gingiva, CEJ, buccal GT3 and ACT and can be reliably used to measure GT and ACT. Both GT3 in maxillary premolars and ACT in maxillary first premolars were more in men than in women. The correlation between buccal GT3 and ACT was moderately positive. This result is similar to that of a previous study, which reported a positive association between GT and bone morphotype using A-mode US and cone-beam CT (CBCT) [19]. However, to the best of our 
knowledge, this is the first study to demonstrate that 15 MHz B-mode US can reliably detect the periodontal tissue structures and buccal GT and ACT of premolars in humans.

Moreover, a significant correlation was found between the US and invasive method while measuring the GT in swine mandibles in the phantom experiment. The GT measured by US was slightly lesser than the GT measured by the invasive method. This difference may have been evident because of the gingival compression caused by direct contact with the probe. Another possibility is that, during the second US, there was an echo from the periosteum that covered the alveolar bone and invasive measurements using the $\mathrm{K}$-file needle could have punctured through the periosteum to hit the bone.

This clinical study involved periodontally healthy individuals who were divided into two groups according to sex. The premolar GT3 in the study sample group ranged from $0.9 \mathrm{~mm}$ to $1.35 \mathrm{~mm}$. This value is a little higher than the $0.9 \mathrm{~mm}$-to- $1.06 \mathrm{~mm}$ range reported by Ganji et al [19] using the A-mode US method at a location $3 \mathrm{~mm}$ apical to the $\mathrm{CEJ}$ in the maxillary premolars and lower than the $1.91 \pm 0.41 \mathrm{~mm}$ reported by Gurlek et al [20] using CBCT at the same locations analyzed in our study. Discrepancies might be caused by differences in the methods, sample sizes and ages as Wara et al [21] reported that participants in a younger age group had significantly thinner mucosa than those in the older age group.

The buccal gingiva of maxillary premolars was thicker in men than that in women. This may be due to natural anatomical differences between the sexes [22,23]. However, not all studies have shown similar results. For example, Vandana et al [24] analyzed the gingiva of maxillary and mandibular anterior teeth by transgingival probing and found that the gingiva was thinner in women than that in men, although this result was only observed in the mandible, not in the maxilla. These anomalies may be due to different methods of measurements or other confounding factors that influence GT, such as racial and genetic factors that need to be further investigated [25]. It is important to investigate the thickness of buccal bone for implant or periodontal treatment. In this study, the $\mathrm{ACT}$ of maxillary first premolars in men was significantly thicker than that in women. This result is consistent with that of a recent study that utilized CBCT to demonstrate that men had greater buccal bone thicknesses in maxillary first premolars [26].

Volumetric changes in soft and hard tissues of the maxillary-premolar region present a potentially unfavorable condition for surgical and non-surgical procedures in oral healthcare. The use of $15 \mathrm{MHz}$ B-mode US to compare the relationship between GT3 and the corresponding buccal ACT in the premolar region is the highlight of this study. The results confirm that the correlation between buccal GT3 and ACT is moderately positive. In this respect, the results of this study may provide the clinicians a reliable method to assess the risk involved and to help in the selection of appropriate treatments for patients.

The limitations of our study include the modest sample size and narrow age range. Large-scale studies that include larger sample sizes with wider age ranges are recommended to confirm these findings.

\section{Conclusions}

In summary, this study demonstrated that $15 \mathrm{MHz}$ B-mode US can yield accurate quantitative data by precisely assessing the periodontal structures of premolars. A survey of the current literature found no other studies that systematically investigated the use of $15 \mathrm{MHz}$ B-mode US for measuring the buccal GT and ACT in humans. From a clinical perspective, the findings of this study suggest that $15 \mathrm{MHz} \mathrm{B}$-mode US has superior diagnostic value in guiding appropriate periodontal treatment, placement of dental implants, and precise plastic surgical methods. The $15 \mathrm{MHz}$ B-mode US could serve as an effective diagnostic modality for analyzing the periodontal tissues, which minimizes discomfort, use of anesthesia, risk of infection, and damage caused by radiation. Further research should be directed toward enhancing the complete understanding of US appearances of periodontal structures in periodontal disease, implants, and malocclusion.

Acknowledgements: We would like to thank the volunteers who participated in this study.

\section{Conflict of interest: none}

\section{References}

1. Eger T, Müller HP, Heinecke A. Ultrasonic determination of gingival thickness. Subject variation and influence of tooth type and clinical features. J Clin Periodontol 1996;23:839845.

2. Kahn S, Almeida RA, Dias AT, Rodrigues WJ, Barceleiro MO, Taba M Jr. Clinical considerations on the root coverage of gingival recessions in thin or thick biotype. Int $\mathrm{J}$ Periodontics Restorative Dent 2016;36:409-415.

3. Fuentes R, Flores T, Navarro P, Salamanca C, Beltrán $\mathrm{V}$, Borie E. Assessment of buccal bone thickness of aesthetic maxillary region: a cone-beam computed tomography study. J Periodontal Implant Sci 2015;45:162168.

4. Huynh-Ba G, Pjeturrson BE, Sanz M, et al. Analysis of the socket bone wall dimenstion in the uper maxilla in relation 
to immediate implant placement. Clin Oral Implants Res 2010;21:37-42.

5. Procopio O, Trojan D, Frigo AC, Paolin A. Use of homologous bone for alveolar crest reconstruction in 483 patients with 5 years' outcomes post implantation. Oral Maxillofac Surg 2019;23:353-363.

6. Voss JO, Dieke T, Doll C, et al. Retrospective long-term analysis of bone level changes after horizontal alveolar crest reconstruction with autologous bone grafts harvested from the posterior region of the mandible. J Periodontal Implant Sci 2016;46:72-83.

7. Stipetic J, Hrala Z, Celebic A. Thickness of masticatory mucosa in the human hard palate and tuberosity dependent on gender and body mass index. Coll Antropol 2005;29:243247.

8. Wara-aswapat iN, Pitiphat W, Chandrapho N, Rattanayatikul C, Karimbux N. Thickness of palatal masticatory mucosa associated with age. J Periodontol 2001;72:1407-1412.

9. De Rouck T, Eghbali R, Collys K, De Bruyn H, Cosyn J. The gingival biotype revisited: transparency of the periodontal probe through the gingival margin as a method to discriminate thin from thick gingiva. J Clin Periodontol 2009;36:428-433.

10. Liu F, Pelekos G, Jin LJ. The gingival biotype in a cohort of Chinese subjects with and without history of periodontal disease. J Periodontal Res 2017;52:1004-1010.

11. Eghbali A, De Rouck T, De Bruyn H, Cosyn J. The gingival biotype assessed by experienced and inexperienced clinicians. J Clin Periodontol 2009;36:958-963.

12. Kan JY, Morimoto T, Rungcharassaeng K, Roe P, Smith $\mathrm{DH}$. Gingival biotype assessment in the esthetic zone: visual versus direct measurement. Int J Periodontics Restorative Dent 2010;30:237-243.

13. Chifor R, Hedesiu M, Bolfa P, et al. The evaluation of 20 $\mathrm{MHz}$ ultrasonography, computed tomography scans as compared to direct microscopy for periodontal system assessment. Med Ultrason 2011;13:120-126.

14. Nikiforidou M, Tsalkis L, Angelopoulos C, Menexes G, Vouros I, Konstantinides A. Classification of periodontal biotypes with the use of CBCT. A cross-sectional study. Clin Oral Investig 2016;20:2061-2071.

15. Younes F, Eghbali A, Raes M, De Bruyckere T, Cosyn J, De Bruyn H. Relationship between buccal bone and gingival thickness revisited using non-invasive registration methods. Clin Oral Implants Res 2016;27:523-528.

16. Slak B, Daabous A, Bednarz W, Strumban E, Maev RG. Assessment of gingival thickness using an ultrasonic dental system prototype: A comparison to traditional methods. Ann Anat 2015;199:98-103.

17. Eghbali A, De Bruyn H, Cosyn J, Kerckaert I, Van Hoof T. Ultrasonic assessment of mucosal thickness around implants: validity, reproducibility, and stability of connective tissue grafts at the buccal aspect. Clin Implant Dent Relat Res 2016;18:51-61.

18. Zimbran A, Dudea S, Dudea D. Evaluation of periodontal tissues using $40 \mathrm{MHz}$ ultrasonography. Preliminary report. Med Ultrason 2013;15:6-9.

19. Ganji KK, Alswilem RO, Abouonq AO, Alruwaili AA, Alam MK. Noninvasive evaluation of the correlation between thickness of the buccal bone and attached gingiva of maxillary premolars. J Esthet Restor Dent 2019;31:240245.

20. Gurlek O, Sonmez S, Guneri P, Nizam N. A novel soft tissue thickness measuring method using cone beam computed tomography. J Esthet Restor Dent 2018;30:516-522.

21. Wara-aswapati N, Pitiphat W, Chandrapho N, Rattanayatikul C, Karimbux N. Thickness of palatal masticatory mucosa associated with age. J Periodontol 2001;72:1407-1412.

22. Müller HP, Heinecke A, Schaller N, Eger T. Masticatory mucosa in subjects with different periodontal phenotypes. J Clin Periodontol 2000;27:621-626.

23. Tzoumpas M, Mohr B, Kurtulus-Waschulewski I, Wahl G. The use of high-frequency ultrasound in the measurement of thickness of the maxillary attached gingiva. Int J Prosthodont 2015;28:374-382.

24. Vandana KL, Savitha B. Thickness of gingiva in association with age, gender and dental arch location. J Clin Periodontol 2005;32:828-830.

25. Studer SP, Allen EP, Rees TC, Kouba A. The thickness of masticatory mucosa in the human hard palate and tuberosity as potential donor sites for ridge augmentation procedures. J Periodontol 1997;68:145-151.

26. Hu X, Lei L, Cui M, Huang Z, Zhang X. Anatomical analysis of periapical bone of maxillary posterior teeth: a cone beam computed tomography study. J Int Med Res 2019;47:4701-4710. 